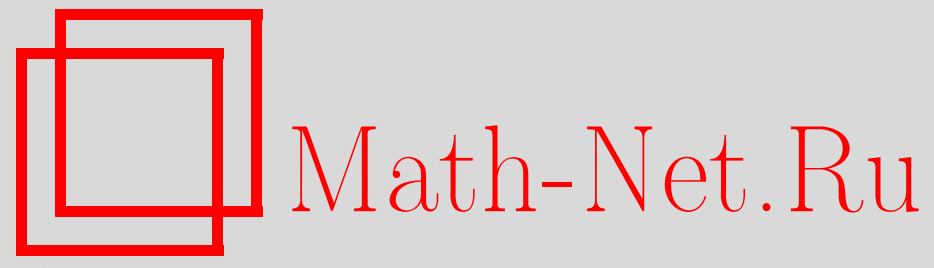

A. M. Kytmanov, S. G. Myslivets, On functions with the boundary Morera property in domains with piecewise-smooth boundary, Vestn. Udmurtsk. Univ. Mat. Mekh. Komp. Nauki, 2021, Volume 31, Issue 1, 50-58

DOI: https://doi.org/10.35634/vm210104

Use of the all-Russian mathematical portal Math-Net.Ru implies that you have read and agreed to these terms of use

http: //www.mathnet.ru/eng/agreement

Download details:

IP: 3.85 .73 .92

April 26, 2023, 16:46:44 
MSC2020: 32A25, 32A40

\author{
(C) A. M. Kytmanov, S. G. Myslivets
}

\title{
ON FUNCTIONS WITH THE BOUNDARY MORERA PROPERTY IN DOMAINS WITH PIECEWISE-SMOOTH BOUNDARY
}

The problem of holomorphic extension of functions defined on the boundary of a domain into this domain is actual in multidimensional complex analysis. It has a long history, starting with the proceedings of Poincaré and Hartogs. This paper considers continuous functions defined on the boundary of a bounded domain $D$ in $\mathbb{C}^{n}, n>1$, with piecewise-smooth boundary, and having the generalized boundary Morera property along the family of complex lines that intersect the boundary of a domain. Morera property is that the integral of a given function is equal to zero over the intersection of the boundary of the domain with the complex line. It is shown that such functions extend holomorphically to the domain $D$. For functions of one complex variable, the Morera property obviously does not imply a holomorphic extension. Therefore, this problem should be considered only in the multidimensional case $(n>1)$. The main method for studying such functions is the method of multidimensional integral representations, in particular, the Bochner-Martinelli integral representation.

Keywords: bounded domain with piecewise-smooth boundary, continuous function, Morera property, Bochner-Martinelli integral representation.

DOI: $10.35634 / \mathrm{vm} 210104$

\section{Introduction}

This article contains some results related to the holomorphic extension of functions that are continuous on the boundary of a bounded domain with a piecewise-smooth boundary to this domain. We will talk about functions that satisfy the Morera boundary condition. It consists in the equality of zero integrals of this function at the intersection of the boundary of this domain with coplex lines or complex planes. E. Greenberg [1] studied functions with the Morera property in the ball (in fact, this result was contained in the article by M. L. Agranovsky and R. E. Walsky [2]). I. Globevnik and E. L. Stout [3] and D. Govekar [4] obtained Morera's boundary theorem for an arbitrary bounded domain with a twice smooth boundary. The local version of Morera's theorem is considered by I. Globevnik [5], D. Govekar-Leban [6]. In the work of S. G. Myslivets [7], functions with the Morera property along complex curves are considered. In the works of the authors [8-11], some families of complex lines sufficient for holomorphic extension of functions are given.

Let $D$ be a bounded domain in $\mathbb{C}^{n}(n>1)$ with a connected piecewise-smooth boundary. (A domain with a piecewise-smooth boundary is a smooth polyhedron.) We denote the ball of radius $\varepsilon>0$ with center at the point $z \in \mathbb{C}^{n}$ by $B(z, \varepsilon)$, and we denote its boundary by $S(z, \varepsilon)$ (that is, $S(z, \varepsilon)=\partial B(z, \varepsilon)$ ). When $z \in \partial D$, we denote by $\tau(z)$ the expression

$$
\tau(z)=\lim _{\varepsilon \rightarrow+0} \frac{\operatorname{vol}\{S(z, \varepsilon) \cap D\}}{\operatorname{vol} S(z, \varepsilon)} .
$$

In other words, $\tau(z)$ is the solid angle of the tangent cone to the surface $\partial D$ at the point $z$. Since we are considering a domain $D$ with piecewise-smooth boundary, the quantity $\tau(z)$ is defined and is not zero. 
Consider one-dimensional complex lines $l_{z, b}$ of the form

$$
l_{z, b}=\left\{\zeta \in \mathbb{C}^{n}: \zeta_{j}=z_{j}+b_{j} t, j=1, \ldots, n, t \in \mathbb{C}\right\}
$$

passing through a point $z \in \mathbb{C}^{n}$ in the direction of a vector $b=\left\{b_{1}, \ldots, b_{n}\right\} \in \mathbb{C P}^{n-1}$ (the direction of $b$ is determined with an accuracy of up to multiplication by a complex number $\lambda \neq 0$ ). By Sard's theorem, for almost all $z \in \mathbb{C}^{n}$ and almost all $b \in \mathbb{C P}^{n-1}$, the intersection $\partial D \cap l_{z, b}$ is a finite set of piecewise-smooth curves (except for the degenerate case where $\partial D \cap l_{z, b}=\varnothing$ ).

Definition 1. We say that a continuous function $f$ on $\partial D(f \in \mathcal{C}(\partial D))$ satisfies the Morera property along a complex plane $l$ of dimension $k, 1 \leqslant k \leqslant n-1$, if

$$
\int_{\partial D \cap l} f(\zeta) \beta(\zeta)=0
$$

for any differential form $\beta$ of type $(k, k-1)$ with constant coefficients.

It is assumed that the plane $l$ transversally intersects the boundary of the domain $D$. If $l_{z, b}$ is a complex line intersecting $\partial D$ transversally, then the Morera property along $l_{z, b}$ consists of the equality

$$
\int_{\partial D \cap l_{z, b}} f(z+b t) d t=\int_{\partial D \cap l_{z, b}} f\left(z_{1}+b_{1} t, \ldots, z_{n}+b_{n} t\right) d t=0
$$

for the given parameterization $\zeta=z+b t$ of the complex line $l_{z, b}$.

For complex lines, we consider a more general condition. Let $k$ be a fixed non-negative integer, then the condition

$$
\int_{\partial D \cap l_{z, b}} f(z+b t) t^{k} d t=\int_{\partial D \cap l_{z, b}} f\left(z_{1}+b_{1} t, \ldots, z_{n}+b_{n} t\right) t^{k} d t=0
$$

we will call the generalized Morera property. For $k=0$, the condition (0.3) becomes the condition $(0.2)$.

We formulate the Theorem proved in the articles $[11,12]$ for domains with a smooth boundary.

Theorem 1. Let $D$ be a bounded domain in $\mathbb{C}^{n}(n>1)$ with a connected smooth boundary and let $k$ be a fixed nonnegative integer and let a function $f \in \mathcal{C}(\partial D)$. If, for almost all $z \in \mathbb{C}^{n}$ and almost all $b \in \mathbb{C P}^{n-1}$, the condition

$$
\int_{\partial D \cap l_{z, b}} f\left(z_{1}+b_{1} t, \ldots, z_{n}+b_{n} t\right) t^{k} d t=0
$$

holds, then $f$ is holomorphically extended to $D$.

For $k=0$, we obtain Theorem from [3]. Here we prove a generalization of the Theorem 1 for domains with a piecewise-smooth boundary. 


\section{$\S 1$. The main result}

Consider the exterior differential form (the Bochner-Martinelli kernel) $U(\zeta, z)$ of type $(n, n-1)$ given by

$$
U(\zeta, z)=\frac{(n-1) !}{(2 \pi i)^{n}} \sum_{k=1}^{n}(-1)^{k-1} \frac{\bar{\zeta}_{k}-\bar{z}_{k}}{|\zeta-z|^{2 n}} d \bar{\zeta}[k] \wedge d \zeta
$$

where $d \bar{\zeta}[k]=d \bar{\zeta}_{1} \wedge \ldots \wedge d \bar{\zeta}_{k-1} \wedge d \bar{\zeta}_{k+1} \wedge \ldots \wedge d \bar{\zeta}_{n}, d \zeta=d \zeta_{1} \wedge \ldots \wedge d \zeta_{n}$.

We consider the Bochner-Martinelli integral

$$
F(z)=\int_{\partial D} f(\zeta) U(\zeta, z), \quad z \notin \partial D,
$$

for the function $f \in \mathcal{C}(\partial D)$. It is a function that is harmonic both in $D$ and $\mathbb{C}^{n} \backslash \bar{D}$, moreover, $F(z)=O\left(|z|^{1-2 n}\right)$ as $|z| \rightarrow \infty$. We will write $F^{+}(z)$ for the integral (1.1) when $z \in D$, and $F^{-}(z)$ when $z \notin \bar{D}$. When $z \in \partial D$, we will consider the Cauchy principal value of the Bochner-Martinelli integral

$$
\text { v.p. } \int_{\partial D} f(\zeta) U(\zeta, z)=\lim _{\varepsilon \rightarrow+0} \int_{\partial D \backslash B(z, \varepsilon)} f(\zeta) U(\zeta, z), \quad z \in \partial D .
$$

We present the Sokhotskiî-Plemelj formulas for the Bochner-Martinelli integral [15, Theorem 2.3]. In [15] these formulas are given for functions $f$ that satisfy the Hölder condition. For continuous functions $f$, they follow from [15, Theorem 3.1]:

$$
\begin{array}{r}
F^{+}(z)=(1-\tau(z)) f(z)+\text { v.p. } \int_{\partial D} f(\zeta) U(\zeta, z), \\
F^{-}(z)=-\tau(z) f(z)+\text { v.p. } \int_{\partial D} f(\zeta) U(\zeta, z), \quad z \in \partial D,
\end{array}
$$

and $F^{+}(z)$ extends continuously to $\bar{D}$, and $F^{-}(z)$ extends continuously to $\mathbb{C}^{n} \backslash D$, and then $F^{+}(z)-F^{-}(z)=f(z)$.

Let's formulate the main result. Let $D$ be a bounded domain in $\mathbb{C}^{n}(n>1)$ with a connected piecewise-smooth boundary, i.e. smooth polyhedron (that is smooth parts of the boundary are of class $\mathcal{C}^{2}$ ) and the complement $\mathbb{C}^{n} \backslash \bar{D}$ is connected.

Theorem 2. Let $D$ be a bounded domain in $\mathbb{C}^{n}(n>1)$ with a connected piecewise-smooth boundary and let for a fixed $k$ and a function $f \in \mathcal{C}(\partial D)$ the condition (0.4) hold for almost all lines $l_{z, b}$ of the form (0.1) intersecting an open set $V \subset D$ (or an open set $V \subset \mathbb{C}^{n} \backslash \bar{D}$ ), then the function $f$ is holomorphically extended into $D$.

\section{$\S 2$. The auxiliary statements}

P r o o f of Theorem is performed for the case of the set $V \subset D$.

Consider complex lines $l_{z, b}$ of the form (0.1) passing through $z$ in the direction of the vector $b \in \mathbb{C P}^{n-1}$.

Lemma 1. The Bochner-Martinelli kernel in the coordinates $t$ and $b$ has the form

$$
U(\zeta, z)=\lambda(b) \wedge \frac{d t}{t}
$$

where $\lambda(b)$ is some differential form of the type $(n-1, n-1)$ in $\mathbb{C P}^{n-1}$ independent of $t$. 
$\mathrm{P}$ r o o f. Assume that $z=0$. Express the Bochner-Martinelli kernel in the variables $t$ and $b$. We obtain

$$
\begin{aligned}
U(\zeta, 0)=\frac{(n-1) !}{(2 \pi i)^{n}} \cdot \frac{\sum_{k=1}^{n}(-1)^{k-1} \bar{\zeta}_{k} d \bar{\zeta}[k] \wedge d \zeta}{|\zeta|^{2 n}}= & \\
=\frac{(-1)^{n-1}(n-1) !}{(2 \pi i)^{n}} \cdot \frac{\sum_{k=1}^{n}(-1)^{k-1} \bar{b}_{k} d \bar{b}[k] \wedge \sum_{k=1}^{n}(-1)^{k-1} b_{k} d b[k]}{|b|^{2 n}} \wedge \frac{d t}{t} & = \\
& =\lambda(b) \wedge \frac{d t}{t} .
\end{aligned}
$$

Lemma 2. If condition (0.4) holds for a point $z \in \mathbb{C}^{n} \backslash \partial D$ and for almost all $b \in \mathbb{C P}^{n-1}$, then

$$
\int_{\partial D_{\zeta}}(\zeta-z)^{\alpha} f(\zeta) U(\zeta, z)=0
$$

where $\alpha=\left(\alpha_{1}, \ldots, \alpha_{n}\right)$ is an arbitrary multi-index such that

$$
\|\alpha\|=\alpha_{1}+\cdots+\alpha_{n}=k+1, \quad \text { and } \quad(\zeta-z)^{\alpha}=\left(\zeta_{1}-z_{1}\right)^{\alpha_{1}} \cdots\left(\zeta_{n}-z_{n}\right)^{\alpha_{n}} .
$$

P r o o f. We use the representation of the Bochner-Martinelli kernel from Lemma 1. Then by Fubini's theorem (this Theorem holds for piecewise-smooth polyhedron (see, for example, [13])), we have

$$
\int_{\partial D}(\zeta-z)^{\alpha} f(\zeta) U(\zeta, z)=\int_{\mathbb{C P}^{n-1}} \lambda(b) \int_{\partial D \cap l} b^{\alpha} t^{k} f(z+b t) d t=0
$$

by condition (0.4).

\section{$\S 3$. Proof of the main result}

Lemma 3. Let condition (2.1) hold for points $z \in V$, then the function $f$ is holomorphically extended into $D$.

P r o o f. If (2.1) holds for $z \in V$, then it also holds for all points $z \in D$ by the real analyticity of the integral in (2.1) and connectivity of the set $\mathbb{C}^{n} \backslash \bar{D}$. Let us rewrite (2.1) in a different form. Introduce the following differential forms $U_{s}(\zeta, z)$, considered for the first time by E. Martinelli [14] (see also [15, § 8]):

$$
\begin{aligned}
U_{s}(\zeta, z)=\frac{(-1)^{s}(n-2) !}{(2 \pi i)^{n}}\left(\sum_{j=1}^{s-1}(-1)^{j} \frac{\bar{\zeta}_{j}-\bar{z}_{j}}{|\zeta-z|^{2 n-2}} d \bar{\zeta}[j, s]+\right. & \\
& \left.+\sum_{j=s+1}^{n}(-1)^{j-1} \frac{\bar{\zeta}_{j}-\bar{z}_{j}}{|\zeta-z|^{2 n-2}} d \bar{\zeta}[s, j]\right) \wedge d \zeta .
\end{aligned}
$$

It is easy to verify that

$$
\bar{\partial}\left(\frac{1}{\zeta_{s}-z_{s}} U_{s}(\zeta, z)\right)=U(\zeta, z)
$$


for $\zeta_{s} \neq z_{s}, s=1, \ldots, n$. Then condition (2.1) can be written in the form

$$
\int_{\partial D} f(\zeta) \bar{\partial}\left((\zeta-z)^{\beta} U_{s}(\zeta, z)\right)=0, \quad z \in D
$$

for all monomials $(\zeta-z)^{\beta}$ with $\|\beta\|=k$.

Let us show that condition (3.1) also holds for the monomials $(\zeta-z)^{\gamma}$ with $\|\gamma\|<k$. Indeed, consider such a monomial $(\zeta-z)^{\gamma}$ and $\|\gamma\|=k-1$. Then (3.1) holds for monomials of the form

$$
(\zeta-z)^{\gamma}\left(\zeta_{m}-z_{m}\right), \quad m=1, \ldots, n
$$

since the degree of these monomials is equal to $k$.

We have

$$
\begin{gathered}
\frac{\partial}{\partial \zeta_{m}}\left((\zeta-z)^{\gamma}\left(\zeta_{m}-z_{m}\right) U_{s}(\zeta, z)\right)=\left(\gamma_{m}+1\right)(\zeta-z)^{\gamma} U_{s}(\zeta, z)- \\
-(n-1)(\zeta-z)^{\gamma} \frac{\left(\zeta_{m}-z_{m}\right)\left(\bar{\zeta}_{m}-\bar{z}_{m}\right)}{|\zeta-z|^{2}} U_{s}(\zeta, z)
\end{gathered}
$$

Summing relations (3.2) with respect to $m$, we obtain

$$
\sum_{m=1}^{n} \frac{\partial}{\partial \zeta_{m}}\left((\zeta-z)^{\gamma}\left(\zeta_{m}-z_{m}\right) U_{s}(\zeta, z)\right)=(\|\gamma\|+1)(\zeta-z)^{\gamma} U_{s}(\zeta, z) .
$$

Since condition (3.1) can be differentiated in $z$ and the derivatives in $z$ and $\zeta$ of the integrand are equal, (3.3) implies that the degree of the monomial in (3.1) can be reduced by 1 . Sequentially reducing this degree, we arrive at the conditions

$$
\int_{\partial D} f(\zeta) \bar{\partial} U_{s}(\zeta, z)=0, \quad z \in D, s=1, \ldots, n
$$

i.e.,

$$
\int_{\partial D}\left(\zeta_{s}-z_{s}\right) f(\zeta) U(\zeta, z)=0, z \in D, s=1, \ldots, n .
$$

Applying the Laplace operator

$$
\Delta=\frac{\partial^{2}}{\partial z_{1} \partial \bar{z}_{1}}+\cdots+\frac{\partial^{2}}{\partial z_{n} \partial \bar{z}_{n}}
$$

to the left-hand side of relation (3.4), we obtain

$$
\frac{\partial}{\partial \bar{z}_{s}} \int_{\partial D} f(\zeta) U(\zeta-z)=0, z \in D, s=1, \ldots, n .
$$

Here, we have used the harmonicity of the kernel $U(\zeta-z)$ and the identity

$$
\Delta(f h)=h \Delta f+f \Delta h+\sum_{j=1}^{n} \frac{\partial f}{\partial \bar{z}_{j}} \frac{\partial h}{\partial z_{j}}+\sum_{j=1}^{n} \frac{\partial f}{\partial z_{j}} \frac{\partial h}{\partial \bar{z}_{j}} .
$$

Therefore, the Bochner-Martinelli-type integral of $f$

$$
F^{-}(z)=\int_{\partial D} f(\zeta) U(\zeta, z)
$$


is a holomorphic function in the domain $\mathbb{C}^{n} \backslash \bar{D}$. Since this set is connected and the BochnerMartinelli integral tends to zero at $|z| \rightarrow \infty$, then it is zero. By Corollary 15.5 in [15], the function $F$ is holomorphically extended into $D$. In [15] these Theorems are given for domains with a smooth boundary. They can also be transferred to our case using [16, Theorem 4]. Then we get that the boundary value of the function $F^{+}$coincides with $f$ on $\partial D$, and we obtain the desired extension of the function $f(z)$.

The proposal is also true if the open set $V \subset D$. In this case, we can show that the integral $F^{-}(z)$ is zero outside $\bar{D}$.

Theorems 1 and 2 are consequences of Lemmas 2 and 3.

Funding. The research is supported by grant of the Russian Science Foundation (project no. 2011-20117).

\section{REFERENCES}

1. Grinberg E. A. A boundary analogue of Morera's theorem in the unit ball of $\mathbb{C}^{n}$, Proceedings of the American Mathematical Society, 1988, vol. 102, no. 1, pp. 114-116. https://doi.org/10.2307/2046041

2. Agranovskii M. L., Val'skii R. É. Maximality of invariant algebras of functions, Siberian Mathematical Journal, 1971, vol. 12, no. 1, pp. 1-7. https://doi.org/10.1007/BF00969135

3. Globevnik J., Stout E. L. Boundary Morera theorems for holomorphic functions of several complex variables, Duke Mathematical Journal, 1991, vol. 64, no. 3, pp. 571-615.

4. Govekar D. Morera conditions along real planes and a characterization of CR functions on boundaries of domains in $\mathbb{C}^{n}$, Mathematische Zeitschrift, 1994, vol. 216, pp. 195-207. https://doi.org/10.1007/BF02572317

5. Globevnik J. A boundary Morera theorem, The Journal of Geometric Analysis, 1993, vol. 3, no. 3, pp. 269-277. https://doi.org/10.1007/BF02921393

6. Govekar-Leban D. Local boundary Morera theorems, Mathematische Zeitschrift, 2000, vol. 233, no. 2, pp. 265-286. https://doi.org/10.1007/PL00004796

7. Myslivets S. G. One boundary version of Morera's theorem, Siberian Mathematical Journal, 2001, vol. 42, no. 5, pp. 952-966. https://doi.org/10.1023/A:1011923929133

8. Kytmanov A. M., Myslivets S. G. On families of complex lines sufficient for holomorphic extension, Mathematical Notes, 2008, vol. 83, no. 3-4, pp. 500-505. https://doi.org/10.1134/S0001434608030231

9. Kytmanov A. M., Myslivets S. G. Some families of complex lines sufficient for holomorphic extension of functions, Russian Mathematics, 2011, vol. 55, no. 4, pp. 60-66. https://doi.org/10.3103/S1066369X11040074

10. Kytmanov A. M., Myslivets S. G. Multidimensional integral representations. Problems of analytic continuation, Cham: Springer, 2015. https://doi.org/10.1007/978-3-319-21659-1

11. Kytmanov A. M., Myslivets S. G. On a certain boundary analog of Morera's theorem, Siberian Mathematical Journal, 1995, vol. 36, no. 6, pp. 1171-1174. https://doi.org/10.1007/BF02106840

12. Kytmanov A. M., Myslivets S. G. Higher-dimensional boundary analogs of the Morera theorem in problems of analytic continuation of functions, Journal of Mathematical Sciences, 2004, vol. 120, no. 6, pp. 1842-1867. https://doi.org/10.1023/B:JOTH.0000020707.81285.06

13. Federer H. Geometric measure theory, Berlin, Heidelberg: Springer, 1969. https://doi.org/10.1007/978-3-642-62010-2

14. Martinelli E. Sopra una dimonstrazione de R. Fueter per un teorema di Hartogs, Commentarii Mathematici Helvetici, 1942, vol. 15, pp. 340-349 (in Italian).

https://link.springer.com/article/10.1007/BF02565649

15. Kytmanov A. M. The Bochner-Martilelli integral and its applications, Basel: Birkhäuser, 1995. https://doi.org/10.1007/978-3-0348-9094-6 
16. Dzhumabaev D. Kh. Holomorphic continuation of functions from closed hypersurfaces with singular edges, Russian Mathematics, 2012, vol. 56, no. 1, pp. 9-18.

https://doi.org/10.3103/S1066369X12010021

Received 16.12.2020

Kytmanov Alexander Mechislavovich, Doctor of Physics and Mathematics, Professor, Department of Mathematical Analysis and Differential Equations, Siberian Federal University, pr. Svobodny, 79, Krasnoyarsk, 660041, Russia.

ORCID: https://orcid.org/0000-0002-7394-1480

E-mail: akytmanov@sfu-kras.ru

Myslivets Simona Glebovna, Doctor of Physics and Mathematics, Professor, Department of Higher and Applied Mathematics, Institute of Mathematics and Mechanics, Siberian Federal University, pr. Svobodny, 79, Krasnoyarsk, 660041, Russia.

ORCID: https://orcid.org/0000-0002-7700-1461

E-mail: smyslivets@sfu-kras.ru

Citation: A. M. Kytmanov, S. G. Myslivets. On functions with the boundary Morera property in domains with piecewise-smooth boundary, Vestnik Udmurtskogo Universiteta. Matematika. Mekhanika. Komp'yuternye Nauki, 2021, vol. 31, issue 1, pp. 50-58. 


\section{А. М. Кымманов, С. Г. Мысливец}

\section{О функциях с граничным свойством Морера в областях с кусочно-гладкой границей}

Ключевые слова: ограниченная область с кусочно-гладкой границей, непрерывная функция, свойство Мореры, интегральное представление Бохнера-Мартинелли.

УДК 517.55

DOI: $10.35634 / \mathrm{vm} 210104$

Проблема голоморфного продолжения функций, определенных на границе области, в эту область актуальна в многомерном комплексном анализе. Она имеет долгую историю, начиная с работ Пуанкаре и Гартогса. В статье рассматриваются непрерывные функции, определенные на границе ограниченной области $D$ в $\mathbb{C}^{n}, n>1$, с кусочно-гладкой границей и обладающие обобщенным граничным свойством Мореры вдоль семейства комплексных прямых, которые пересекают границу области. Свойство Мореры состоит в том, что интеграл заданной функции равен нулю по пересечению границы области с комплексной прямой. Показано, что такие функции голоморфно продолжаются в область $D$. Для функций одной комплексной переменной свойство Мореры, очевидно, не влечет голоморфного продолжения. Поэтому эту проблему следует рассматривать только в многомерном случае $(n>1)$. Основным методом изучения таких функций является метод многомерных интегральных представлений, в частности интегрального представления Бохнера-Мартинелли.

Финансирование. Исследование выполнено за счет гранта Российского научного фонда (проект № 20-11-20117).

\section{СПИСОК ЛИТЕРАТУРЫ}

1. Grinberg E. A. A boundary analogue of Morera's theorem in the unit ball of $\mathbb{C}^{n} / /$ Proceedings of the American Mathematical Society. 1988. Vol. 102. No. 1. P. 114-116. https://doi.org/10.2307/2046041

2. Аграновский М. Л., Вальский Р.Э. Максимальность инвариантных алгебр функций // Сиб. матем. журн. 1971. T. 12. № 1. С. 3-12. http://mi.mathnet.ru/smj5850

3. Globevnik J., Stout E. L. Boundary Morera theorems for holomorphic functions of several complex variables // Duke Mathematical Journal. 1991. Vol. 64. No. 3. P. 571-615.

4. Govekar D. Morera conditions along real planes and a characterization of CR functions on boundaries of domains in $\mathbb{C}^{n} / /$ Mathematische Zeitschrift. 1994. Vol. 216. P. 195-207. https://doi.org/10.1007/BF02572317

5. Globevnik J. A boundary Morera theorem // The Journal of Geometric Analysis. 1993. Vol. 3. No. 3. P. 269-277. https://doi.org/10.1007/BF02921393

6. Govekar-Leban D. Local boundary Morera theorems // Mathematische Zeitschrift. 2000. Vol. 233. No. 2. P. 265-286. https://doi.org/10.1007/PL00004796

7. Мысливец С. Г. Об одном граничном варианте теоремы Морера // Сиб. матем. журн. 2001. Т. 42. № 5. C. 1136-1146. http://mi.mathnet.ru/smj1411

8. Кытманов А. М., Мысливец С.Г. О семействах комплексных прямых, достаточных для голоморфного продолжения // Математические заметки. 2008. Т. 83. Вып. 4. С. 545-551. https://doi.org/10.4213/mzm3770

9. Кытманов А. М., Мысливец С.Г. О некоторых семействах комплексных прямых, достаточных для голоморфного продолжения функций // Изв. вузов. Математика. 2011. № 4. С. 72-80. http://mi.mathnet.ru/ivm7291

10. Kytmanov A.M., Myslivets S.G. Multidimensional integral representations. Problems of analytic continuation. Cham: Springer, 2015. https://doi.org/10.1007/978-3-319-21659-1

11. Кытманов А. М., Мысливец С. Г. Об одном граничном аналоге теоремы Морера // Сиб. матем. журн. 1995. Т. 36. № 6. С. 1350-1353. http://mi.mathnet.ru/smj562 
12. Kytmanov A. M., Myslivets S. G. Higher-dimensional boundary analogs of the Morera theorem in problems of analytic continuation of functions // Journal of Mathematical Sciences. 2004. Vol. 120. No. 6. P. 1842-1867. https://doi.org/10.1023/B:JOTH.0000020707.81285.06

13. Federer H. Geometric measure theory. Berlin, Heidelberg: Springer, 1969. https://doi.org/10.1007/978-3-642-62010-2

14. Martinelli E. Sopra una dimonstrazione de R. Fueter per un teorema di Hartogs // Commentarii Mathematici Helvetici. 1942. Vol. 15. P. 340-349 (in Italian). https://link.springer.com/article/10.1007/BF02565649

15. Кытманов А. М. Интеграл Бохнера-Мартинелли и его применения. Новосибирск: Наука, 1992.

16. Джумабаев Д.Х. Голоморфное продолжение функций с замкнутых гиперповерхностей с сингулярными ребрами // Изв. вузов. Матем. 2012. № 1. С. 12-21. http://mi.mathnet.ru/ivm8414

Поступила в редакцию 16.12 .2020

Кытманов Александр Мечиславович, д. ф.-м. н., профессор, кафедра математического анализа и дифференциальных уравнений, Сибирский федеральный университет, 660041, Россия, г. Красноярск, пр. Свободный, 79.

ORCID: https://orcid.org/0000-0002-7394-1480

E-mail: akytmanov@sfu-kras.ru

Мысливец Симона Глебовна, д. ф.-м. н., профессор, кафедра высшей и прикладной математики, Сибирский федеральный университет, 660041, Россия, г. Красноярск, пр. Свободный, 79.

ORCID: https://orcid.org/0000-0002-7700-1461

E-mail: smyslivets@sfu-kras.ru

Цитирование: А. М. Кытманов, С.Г. Мысливец. О функциях с граничным свойством Морера в областях с кусочно-гладкой границей // Вестник Удмуртского университета. Математика. Механика. Компьютерные науки. 2021. Т. 31. Вып. 1. С. 50-58. 